\title{
Meaning in life among adolescents: Factorial invariance of the purpose in life test and buffering effect on the relationship between emotional dysregulation and hopelessness
}

\author{
Joaquín García-Alandete ${ }^{1}$ (D) | Blanca Gallego Hernández de Tejada ${ }^{2}$ | \\ Sandra Pérez Rodríguez ${ }^{3}$ | José H. Marco-Salvador ${ }^{3}$ (i)
}

\author{
${ }^{1}$ Dpto. de Metodología, Neuropsicobiología y \\ Psicología Básica y Social, Universidad \\ Católica de Valencia San Vicente Mártir, \\ Valencia, Spain \\ ${ }^{2}$ Escuela de Doctorado, Universidad Católica \\ de Valencia San Vicente Mártir, Valencia, \\ Spain \\ ${ }^{3}$ Dpto. de Personalidad, Evaluación y \\ Tratamientos Psicológicos, Universidad \\ Católica de Valencia San Vicente Mártir, \\ Valencia, Spain \\ Correspondence \\ Dr. Joaquín García-Alandete, Dpto. de \\ Metodología, Neuropsicobiología y Psicología \\ Básica y Social, Universidad Católica de \\ Valencia San Vicente Mártir, Valencia, Spain. \\ Email: ximo.garcia@ucv.es
}

\begin{abstract}
Objective: The purpose of the present study was threefold: first, to analyse the psychometric properties of a 10-item Spanish version of the Purpose in Life Test, which assesses meaning in life (MiL), in a sample of community adolescents; second, to analyse the differences between the age and gender groups; and third, to analyse whether MiL buffers the relationship between emotional dysregulation and hopelessness.
\end{abstract}

Method: Participants were 1,599 adolescents from 12 to 19 years old, $M=15.69$, $S D=2.14$. The Purpose in Life Test-10 Items, the Beck Hopelessness Scale, and the Difficulties in Emotional Regulation Scale were used.

Results: A nine-item version showed good fit, psychometric properties (internal consistency, construct, and concurrent validity), and factorial invariance across gender and age (12-15 years/16-19 years). Difference in MiL between boys and girls was not significant, whereas between age groups was significant. MiL had a strong buffering effect on the relationship between emotional dysregulation and hopelessness.

Discussion: It is desirable to promote the sense of MiL in adolescents. MiL plays a significant and strong mediator role in the relationship between emotional dysregulation and hopelessness, reinforcing the positive role of MiL in mental health and as a resource for facing adversity.

\section{KEYWORDS}

adolescents, buffering effect, emotional dysregulation, hopelessness, meaning in life, Purpose in Life Test

\section{1 | INTRODUCTION}

Adolescence is a significant developmental stage for building a positive personal identity, which is related to mental health (e.g. Chen, Lay, Wu, \& Yao, 2007), emotional stability and adjustment (Crocetti, Rubini, Luyckx, \& Meeus, 2008), and psychological wellbeing (e.g., Sandhu, Singh, Tung, \& Kundra, 2012), whereas a poor personal identity in adolescence is related to depression, hopelessness, and suicidal tendencies (e.g., Ramgoon, Bachoo, Patel, \& Paruk,
2006; Vatan, Lester, \& Gunn, 2014). Likewise, emotional dysregulation is linked to adolescent psychopathology (e.g., McLaughlin, Hatzenbuehler, Mennin, \& Nolen-Hoeksema, 2011). However, meaning in life (MiL) plays a strong protector role against adolescent psychopathology (e.g., Brassai, Piko, \& Steger, 2012).

The present study offers a threefold analysis of MiL, hopelessness, and emotional dysregulation in a sample of Spanish community adolescents. First, it analyses the psychometric properties of a Spanish version of the Purpose in Life Test (PIL) for assessing MiL; second, it 
analyses whether there are differences in MiL related to age and gender; and third, it analyses the buffering role of MiL in the relationship between hopelessness and emotional dysregulation.

\section{1 | Meaning in life}

According to Frankl (1988), the founder of logotherapy, the most important human motivation involves perceiving and experiencing that one's life is meaningful. This author emphasized the role of selftranscendence and creative, experiential, and attitudinal values in the development of a sense of existential fulfilment. Many definitions have been used to describe MiL, such as a sense of fulfilment or coherence in life, self-actualization, goal directness, sense of purpose, autonomy, and authentic living, among others (e.g., Wong, 2016). MiL comprises meaning and purpose, which are closely related constructs and can be used interchangeably. However, value, significance, and importance can be synonyms of meaning, whereas goals, intentions, and objectives define purpose (Lent, 2013; Steger, Frazier, Oishi, \& Kaler, 2006). For parsimony, in this article, we use the term "meaning" to refer both meaning and purpose.

The most widely used instrument to assess MiL is the PIL (Crumbaugh \& Maholick, 1969), a 20-item Likert-type scale with seven response categories related to different aspects of MiL: meaning, purpose, or mission in life (items 3, 4, 7, 12, 17, and 20); satisfaction with one's life (items 1, 2, 5, 6, 9, and 19); freedom (items 13, 14, and 18); fear of death (item 15); and life evaluation (item 10; Schulenberg \& Melton, 2010). Although the PIL has shown good reliability (e.g., Jonsén et al., 2010; Melton \& Schulenberg, 2008), its factorial structure has been analysed in various studies, with important differences in the results (e.g., Rosa, García-Alandete, Sellés, Bernabé, \& Soucase, 2012; Schulenberg \& Melton, 2010).

The PIL has been used in several studies with adolescents (e.g., Bronk, Hill, Lapsley, Talib, \& Finch, 2009; Schulenberg, Smith, Drescher, \& Buchanan, 2016). However, to our knowledge, its psychometric properties have only been analysed in adolescents on two occasions. Walters and Klein (1980), in a study with 1,082 North American high school students, obtained empirical evidence for a bifactorial structure: Despair and Enthusiasm. The internal consistency coefficient yielded by the Despair factor scale, $\alpha=0.83$, was quite similar to the split-half correlation coefficient reported earlier by Crumbaugh (1968). Shek (1988), in a sample of 2,140 Chinese high school students (ages ranging from 11 to 20 years), found high internal consistency, $\alpha=0.84$, of the Chinese version of the PIL, and a five-factor model using exploratory procedures: Quality of life, Meaning of existence, Death, Choice, and Retirement. By randomly dividing the total sample into two subsamples, high coefficients of congruence were found for factors 1, 2, 3, and 5. An alternative analysis with a two-factor solution showed that two general factors could be extracted, namely, Existence and Death.

With regard to the possible influence of gender on the total score on the PIL, the results found in various studies are inconclusive. On the one hand, in some studies, women obtained significantly higher scores than men on MiL (e.g., Molasso, 2006), whereas other studies reported higher, but not statistically significant, scores in women (Coffield \& Buckalew, 1986; Jackson \& Coursey, 1988; Sallee \&

\section{Key Practitioner Message}

- It is important to promote a sense of satisfaction with life and purpose, the clarification of personal identity and life goals, and empowerment in adolescents, in order to contribute to the feeling that their lives are meaningful, strengthen commitment to their lives, and protect them from psychopathology and risk behaviours.

- Psychologists in general and psychotherapists who treat adolescents diagnosed with mental or behavioural disorders should acquire specific therapeutic strategies.

- Meaning-centred therapy might be a useful approach in achieving these goals.

Casciani, 1976). On the other hand, some studies showed that men obtained a significant, higher average score than women on MiL (e.g., Mak \& Shek, 1990), whereas other studies did not find any sexrelated differences in MiL in adolescents and young people (e.g., Flood \& Boyd, 2008; Steger, Oishi, \& Kashdan, 2009).

However, no studies have been carried out on the psychometric characteristics in the different age groups of adolescence with the $\mathrm{PIL}$, considering the possible influences of gender and age. For these reasons, we intend to explore differences in the understanding of MiL in different periods of adolescence.

\subsection{MiL in adolescents}

Although having a sense of MiL is important across the life span (e.g., Steger et al., 2009), it would be especially important during adolescence, because it is a particularly sensitive stage for the development of a healthy personal identity, which can reinforce purposeful commitments and hopes to accomplish towards in life (e.g., Bronk, 2011; Damon, 2008). To a large extent, an authentic and goal-oriented life is the result of personal development during adolescence (e.g., Burrow, O'Dell, \& Hill, 2010; Côté, 2002). Therefore, to develop a strong sense of MiL during adolescence could be a resource of resilience, a strong protective factor for successfully dealing with life's negative circumstances, psychopathological symptoms, and self-disturbances (Brassai, Piko, \& Steger, 2015; Brouzos, Vassilopoulos, \& Boumpouli, 2016; Fu \& Law, 2017; Henry et al., 2014; Zhang, Li, Chen, Ewalds-Kvist, \& Liu, 2017). Likewise, MiL is a strong predictor of wellbeing, mental health, and healthy behaviours both during adolescence (e.g., Wilchek-Aviad \& Ne'eman-Haviv, 2018; Wilchek-Aviad \& Ne'eman-Haviv, 2016; Wilchek-Aviad, Ne'eman-Haviv, \& Malka, 2016) and during adulthood (e.g., Lightsey, 2006; Ostrowski, 2015).

\section{3 | Emotional dysregulation in adolescents}

Emotional dysregulation can be defined as "the frequent and intense experience of emotions combined with an inability to cope with their occurrence" (Matusiewicz, Weaverling, \& Lejuez, 2014, 177) or as personal difficulties/failure in modifying the intensity and/or duration of 
one's emotions in response to environmental demands (e.g., Gross, 2015). Several studies report that emotional dysregulation is an important predictor of the development and maintenance of psychopathology in the adolescent population (e.g., Chesney, Goodwin, \& Fazel, 2014; Hansson, Daukantaité, \& Johnsson, 2017; Ibraheim, Kalpakci, \& Sharp, 2017; McLaughlin et al., 2011; Perlman et al., 2012), whereas emotional regulation predicts psychological well-being and mental health and is an important resource for facing adversity in adolescents (e.g., Caston \& Mauss, 2011; Kuppens \& Verduyn, 2015).

\section{4 | Hypotheses}

The purpose of the present study was threefold: first, to analyse the psychometric properties of a 10-item Spanish version of the PIL in a sample of community adolescents; second, to analyse the differences between the age and gender groups; and third, to analyse whether MiL buffers the relationship between emotional dysregulation and hopelessness. We hypothesized that the factor structure of the scale would be confirmed, that there would be strong measurement invariance across age and gender groups, that differences between boys and girls would not be significant, and that MiL would moderate the relationship between emotional dysregulation and hopelessness.

\section{2 | METHOD}

\section{1 | Participants}

Participants were 1,599 Spanish adolescents from 12 to 19 years old, $M=15.69, S D=2.14$. The mean age was $15.37, S D=2.04$, for the boys and $15.93, S D=2.17$, for the girls. Table 1 shows the distribution of the participants by gender and age.

The sample comprised college and university students who were recruited through classroom announcements and consent letters sent home. They were from several cities in Spain. The inclusion criteria were that participants had to be male or female adolescents between 12 and 19 years old with the informed consent signed by them and/or their parents. We followed the World Health Organization (WHO, 2003) definition of adolescents as people from 10 to 19 years old. The WHO classifies three periods within adolescence: early adolescence (from 10 to 13 years old), characterized by the beginning of abstract thinking; midadolescence (from 14 to 15 years old), when the individual develops a greater sense of identity and thinking becomes more reflective; and later adolescence (from 16 to 19 years

TABLE 1 Distribution of the participants according to gender and age

\begin{tabular}{|c|c|c|c|c|c|c|c|c|c|c|}
\hline & & \multicolumn{8}{|l|}{ Age } & \multirow[b]{2}{*}{ Total } \\
\hline & & 12 & 13 & 14 & 15 & 16 & 17 & 18 & 19 & \\
\hline \multirow[t]{2}{*}{ Boys } & $n$ & 64 & 74 & 132 & 114 & 109 & 95 & 60 & 65 & 713 \\
\hline & $\%$ & 9 & 10.4 & 18.5 & 16 & 15.3 & 13.3 & 8.4 & 9.1 & 100 \\
\hline \multirow[t]{2}{*}{ Girls } & $n$ & 57 & 87 & 112 & 125 & 140 & 103 & 105 & 157 & 886 \\
\hline & $\%$ & 6.4 & 9.8 & 12.6 & 14.1 & 15.8 & 11.6 & 11.9 & 17.7 & 100 \\
\hline \multirow[t]{2}{*}{ Total } & $n$ & 121 & 161 & 244 & 239 & 249 & 198 & 165 & 222 & 1,599 \\
\hline & $\%$ & 7.6 & 10.1 & 15.3 & 14.9 & 15.6 & 12.4 & 10.3 & 13.9 & 100 \\
\hline
\end{tabular}

old), when the adolescent has a different identity, more ideas, and established opinions (WHO, 2003). The exclusion criterion was that the students and/or their parents did not agree to participate in the study. Participants were given appropriate instructions to complete the assessment protocol. All the participants understood Spanish.

\section{2 | Instruments}

\subsection{1 | PIL-10 Items (PIL-10; García-Alandete, Rosa, \& Sellés, 2013)}

This scale is a two-factor 10-item version of the original Crumbaugh and Maholick (1969) PIL to assess MiL. The items on the PIL-10 are answered on a Likert scale (from 1 to 7, with a specific anchor for each item) that assesses Satisfaction and Meaning in Life (SML factor) and Purposes and Goals in Life (PGL factor). The total score ranges from 10 to 70. In the present study, the PIL-10 and the SML factor showed high internal consistency, $\alpha=0.88$ and $\alpha=0.85$, respectively, and the PGL factor showed acceptable internal consistency, $\alpha=0.73$.

\subsection{2 | Beck Hopelessness Scale (BHS; Beck, Weissman, Lester, \& Trexler, 1974)}

This is a 20-item scale with dichotomous items (true-false) designed to assess negative expectations about the future. We used the Spanish version by Viñas et al. (2004). Level of hopelessness is a predictive factor for suicide in the clinical population. In our data, the internal consistency of the BHS was adequate, $\alpha=0.81$ (based on $77.2 \%$ of the sample, $n=1,234$ ).

\subsection{3 | Difficulties in Emotional Regulation Scale (DERS; Gratz \& Roemer, 2004)}

This scale assesses different features of the emotion regulation process in adults. The Spanish version used in this study (Hervás \& Jódar, 2008) consists of 28 Likert-type items with five response levels. In our sample, the total scale showed satisfactory internal consistency, $\alpha=0.89$ (based on $77.9 \%$ of the sample, $n=1,246$ ).

\section{3 | Procedure}

This research was approved by the university's ethics committee prior to its implementation (research code UCV2013-2014/0023). We called or wrote to the directors of 22 Spanish high schools, of which nine finally participated (40.91\%), and one Spanish university to explain the aim of the study, and we asked if they were interested in collaborating in this research. Convenience sampling was used to choose the schools. If the director of the school agreed to participate, we had individual meetings with him/her. Then the academic head of each school informed the parents of future participants (if they were underage) or the students (in the case of undergraduates) about the study. Informed consent was obtained from all the individual participants included in the study (who participated voluntarily and anonymously and did not receive any compensation for their participation). In the case of the underage participants, the parents first gave written consent for participation, and then the students provided written agreement. Participants filled out the questionnaires during their normal school day through the online Survey Monkey platform. 


\section{4 | Statistical analyses}

Descriptive statistics, skewness, kurtosis, internal consistency, itemscale correlations, and the change in the Cronbach's alpha of the PIL-10 when each item was deleted were calculated. The Cronbach's alpha for this scale increased when Item 6 was removed. Thus, a nine-item version of the PIL was obtained. This scale was called the PIL for Adolescents (PIL-A). Then, a Multi-Group Confirmatory Factor Analysis (CFA) was carried out to evaluate the structural invariance of the PIL-A across gender and age, using the EQS 16.1 program (Bentler, 2006). Three increasingly restrictive models were iteratively examined to determine the degree of model invariance across both the gender and age of the participants (Vandenberg \& Lance, 2000). To establish configural invariance and evaluate whether the same factors exist across groups, the baseline fit of the measurement model was evaluated in two separate CFAs with each group (male/female, 12-15 years/16-19 years). Metric invariance was evaluated by constraining factor loadings to equivalence across groups, whereas factor variances, factor covariance, and error variances were freely estimated. Finally, factor variances and covariance were also constrained to equivalence across groups to explore factor variance/ covariance invariance. Only the error variances were freely estimated in this most restrictive model.

Because Mardia's coefficient, normalized estimate, was greater than 5, multivariate normality was not assumed, and Robust Maximum Likelihood estimation was used (Satorra \& Bentler, 2001). Fit indices included: (a) the Comparative Fit Index (CFI), an absolute index with values $\geq 0.90$ indicating acceptable fit and values $\geq 0.95$ indicating good model fit; and (b) the Root Mean Square Error of Approximation (RMSEA), an index with values $\leq 0.08$ indicating acceptable model fit and values $\leq 0.05$ indicating good model fit (e.g., Hair, Anderson, Tatham, \& Black, 2006).

To evaluate the fit difference between nested models, the differences between the $\mathrm{CFI}$ fit index $(\triangle \mathrm{CFI})$ and the RMSEA index ( $\triangle$ RMSEA) were used: Values $\leq 0.01$ in $\triangle C F I$ (Cheung \& Rensvold, 2002) and an increasing <0.015 in the RMSEA (Chen, 2007) indicate nonsignificant differences between the models.

Descriptive statistics, internal consistency, and construct validity (both convergent and discriminant validity) of the PIL-A, as well as the differences between women and men and between age groups, were calculated. Because Cronbach's alpha tends to underestimate reliability when there are few items and ordinal scales (as in the current study), the Composite Reliability (CR) was also calculated (e.g., Brown, 2015; according to Hair et al., 2006, the CR should be $>0.70$ ). The convergent validity of the PIL-A and both the SML and PGL factors was reported with the Average Variance Extracted (AVE; according to Hair et al., 2006, the AVE should be >0.50). The discriminant validity of the PIL-A was obtained by squaring the correlation between the factors of the scale. To report the concurrent validity of the PIL-A, the correlations with both the BHS and DERS were analysed. A multiple hierarchical regression was conducted to determine whether MiL moderates the relationship between emotional dysregulation and hopelessness.

The SPSS Statistics 22.0 program for Windows (IBM, 2013) was used for the descriptive statistics, estimation of the internal consistency of the PIL, BHS, and DERS, differences in the PIL-A based on gender and age, correlations between the PIL-A, the BHS, and the DERS, and regression analysis. Interpretations of effect sizes for the $t$ test differences and $r$ were based on Cohen (1988). For the CFA, the EQS 6.1 for Windows (Bentler, 2006) was used.

\section{3 | RESULTS}

\section{1 | Descriptive statistics and preliminary analysis of the PIL-10}

The means and standard deviations for the PIL-10 were the following: overall sample, $M=53.13, S D=9.55 ; 12$ - to 15 -year-old group, $M=52.52, S D=9.81$; 16 - to 19 -year-old group, $M=53.69, S D=9.28$; boys, $M=52.51, S D=9.49$; girls, $M=52.51, S D=9.46$.

Table 2 shows the descriptive statistics, skewness, kurtosis of the items on the PIL-10, the scale's alpha if an item is removed, and itemscale correlations. The correlation between Item 6 (After retiring, I would: Loaf completely the rest of my life/Do some of the exciting things I have always wanted to do) and the scale was below 0.50 in the overall sample and in the 12- to 15-year-old and 16- to 19-yearold groups. The internal consistency of the PIL-10 would increase by removing Item 6. For these reasons, Item 6 was removed, and therefore, the scale was reduced to nine items and called the PIL-A.

\section{2 | Structural validity of the PIL-A across gender and age}

Table 3 shows the fit statistics for the baseline, configural invariance, metric invariance, and factor invariance models for the PIL-A. Mardia's coefficient, normalized estimate, suggested using the maximum likelihood solution with robust methods (Bentler, 2006).

\subsection{1 | Configural invariance}

The two-factor model for the PIL-A showed an acceptable fit in the gender and age groups, demonstrating configural invariance. For responses provided by the gender and age groups, all estimated standardized factor loadings for the PIL-A were significant, $p<0.05$ (Table 4).

\subsection{2 | Metric invariance}

Acceptable model fit was found for the metric invariance model, that is, equivalence of the factor loadings across groups (Table 3). The $\mathrm{CFI}$ values for the metric model were slightly lower than for the configural model.

\subsection{3 | Factor variance/covariance invariance}

This most restrictive model had an acceptable fit (Table 3), showing that the association between satisfaction and MiL and purpose in life was equivalent across groups (boys/girls, 12-15 years/16-19 years).

\section{3 | Means and standard deviations of the PIL-A}

The means and standard deviations for the PIL-A were the following: overall sample, $M=47.21, S D=8.94 ; 12$ - to 15 -year-old group, 
TABLE 2 Descriptive statistics, skewness, and kurtosis of the items on the PIL-10, scale's alpha if item is removed, and item-scale correlations

\begin{tabular}{|c|c|c|c|c|c|c|c|}
\hline & Item & $M$ & $S D$ & Skewness & Kurtosis & $r_{\text {(item-scale) }}$ & $\begin{array}{l}\text { PIL-10 alpha if } \\
\text { item removed }\end{array}$ \\
\hline \multirow[t]{10}{*}{$\begin{array}{l}\text { Overall sample } \\
\qquad(n=1,599)\end{array}$} & $\begin{array}{l}\text { 1. I am usually: Completely bored/Exuberant, } \\
\text { enthusiastic }\end{array}$ & 4.75 & 1.18 & $-0.62(0.06)$ & $0.84(0.12)$ & $0.67^{*}$ & 0.87 \\
\hline & $\begin{array}{l}\text { 2. Life to me seems: Completely routine/Always } \\
\text { exciting }\end{array}$ & 4.63 & 1.47 & $-0.57(0.06)$ & $0.04(0.12)$ & $0.74^{*}$ & 0.86 \\
\hline & $\begin{array}{l}\text { 3. In life I have: No goals or aims at all/Very clear } \\
\text { goals and aims }\end{array}$ & 5.79 & 1.21 & $-1.13(0.06)$ & $1.56(0.12)$ & $0.67^{*}$ & 0.87 \\
\hline & $\begin{array}{l}\text { 4. Every day is: Exactly the same/Constantly new and } \\
\text { different }\end{array}$ & 4.72 & 1.51 & $-0.38(0.06)$ & $-0.17(0.12)$ & $0.70^{*}$ & 0.87 \\
\hline & $\begin{array}{l}\text { 5. If I could choose, I would: Prefer never to have been } \\
\text { born/Like nine more lives just like this one }\end{array}$ & 5.51 & 1.35 & $-0.95(0.06)$ & $0.82(0.12)$ & $0.69^{*}$ & 0.87 \\
\hline & $\begin{array}{l}\text { 6. After retiring I would: Loaf completely the rest of my } \\
\text { life/Do some of the exciting things I have always } \\
\text { wanted to do }\end{array}$ & 5.93 & 1.47 & $-1.58(0.06)$ & $2.21(0.12)$ & $0.48^{*}$ & 0.89 \\
\hline & $\begin{array}{l}\text { 7. My life is: Empty, filled with despair/Running over } \\
\text { with exciting good things }\end{array}$ & 5.33 & 1.28 & $-0.80(0.06)$ & $0.59(0.12)$ & $0.78^{*}$ & 0.86 \\
\hline & $\begin{array}{l}\text { 8. When thinking about my life I: Often wonder } \\
\text { why I exist/Always see a reason for my being here }\end{array}$ & 5.43 & 1.67 & $-1.01(0.06)$ & $0.31(0.12)$ & $0.77^{*}$ & 0.86 \\
\hline & $\begin{array}{l}\text { 9. I regard my ability to find a } \\
\text { meaning, a purpose, or mission in } \\
\text { life as: Practically none/Very great }\end{array}$ & 5.45 & 1.30 & $-0.85(0.06)$ & $0.69(0.12)$ & $0.74^{*}$ & 0.86 \\
\hline & $\begin{array}{l}\text { 10. I have discovered: No mission or purpose in } \\
\text { life/Clear-cut goals and a satisfying life purpose }\end{array}$ & 5.59 & 1.28 & $-0.90(0.06)$ & $0.79(0.12)$ & $0.71^{*}$ & 0.87 \\
\hline \multirow[t]{10}{*}{$\begin{array}{l}12-15 \text { years } \\
(n=765)\end{array}$} & $\begin{array}{l}\text { 1. I am usually: Completely bored/Exuberant, } \\
\text { enthusiastic }\end{array}$ & 4.71 & 1.20 & $-0.72(0.09)$ & $1.03(0.17)$ & $0.65^{*}$ & 0.87 \\
\hline & $\begin{array}{l}\text { 2. Life to me seems: Completely routine/Always } \\
\text { exciting }\end{array}$ & 4.63 & 1.49 & $-0.55(0.09)$ & $0.03(0.17)$ & $0.76^{*}$ & 0.86 \\
\hline & $\begin{array}{l}\text { 3. In life I have: No goals or aims at all/Very clear } \\
\text { goals and aims }\end{array}$ & 5.75 & 1.23 & $-1.03(0.09)$ & $1.13(0.17)$ & $0.66^{*}$ & 0.87 \\
\hline & $\begin{array}{l}\text { 4. Every day is: Exactly the same/Constantly } \\
\text { new and different }\end{array}$ & 4.66 & 1.55 & $-0.41(0.09)$ & $-0.20(0.17)$ & $0.69^{*}$ & 0.87 \\
\hline & $\begin{array}{l}\text { 5. If I could choose, I would: Prefer never } \\
\text { to have been born/Like nine more lives } \\
\text { just like this one }\end{array}$ & 5.42 & 1.46 & $-0.95(0.09)$ & $0.60(0.17)$ & $0.73^{*}$ & 0.86 \\
\hline & $\begin{array}{l}\text { 6. After retiring I would: Loaf completely } \\
\text { the rest of my life/Do some of the exciting } \\
\text { things I have always wanted to }\end{array}$ & 5.88 & 1.49 & $-1.49(0.09)$ & $1.88(0.17)$ & $0.48^{*}$ & 0.89 \\
\hline & $\begin{array}{l}\text { 7. My life is: Empty, filled with despair/Running over } \\
\text { with exciting good things }\end{array}$ & 5.27 & 1.32 & $-0.78(0.09)$ & $0.43(0.17)$ & $0.77^{*}$ & 0.86 \\
\hline & $\begin{array}{l}\text { 8. When thinking about my life I: Often wonder why } \\
\text { I exist/Always see a reason for my being here }\end{array}$ & 5.28 & 1.76 & $-0.91(0.09)$ & $-0.02(0.17)$ & $0.77^{*}$ & 0.86 \\
\hline & $\begin{array}{l}\text { 9. I regard my ability to find a meaning, } \\
\text { a purpose, or mission in life as: Practically } \\
\text { none/Very great }\end{array}$ & 5.39 & 1.31 & $-0.84(0.09)$ & $0.76(0.17)$ & $0.72^{*}$ & 0.86 \\
\hline & $\begin{array}{l}\text { 10. I have discovered: No mission or } \\
\text { purpose in life/Clear-cut goals and a } \\
\text { satisfying life purpose }\end{array}$ & 5.54 & 1.32 & $-0.88(0.09)$ & $0.71(0.17)$ & $0.70^{*}$ & 0.87 \\
\hline \multirow[t]{10}{*}{$\begin{array}{l}16-19 \text { years } \\
(n=834)\end{array}$} & $\begin{array}{l}\text { 1. I am usually: Completely bored/Exuberant, } \\
\text { enthusiastic }\end{array}$ & 4.79 & 1.15 & $-0.50(0.09)$ & $0.60(0.17)$ & $0.69^{*}$ & 0.87 \\
\hline & $\begin{array}{l}\text { 2. Life to me seems: Completely routine/Always } \\
\text { exciting }\end{array}$ & 4.63 & 1.45 & $-0.59(0.09)$ & 0.05 (0.169) & $0.73^{*}$ & 0.87 \\
\hline & $\begin{array}{l}\text { 3. In life I have: No goals or aims at all/Very clear } \\
\text { goals and aims }\end{array}$ & 5.83 & 1.18 & $-1.23(0.09)$ & $2.05(0.17)$ & $0.69^{*}$ & 0.87 \\
\hline & $\begin{array}{l}\text { 4. Every day is: Exactly the same/Constantly } \\
\text { new and different }\end{array}$ & 4.76 & 1.47 & $-0.34(0.09)$ & $-0.17(0.17)$ & $0.72^{*}$ & 0.87 \\
\hline & $\begin{array}{l}\text { 5. If I could choose, I would: Prefer never } \\
\text { to have been born/Like nine more lives } \\
\text { just like this one }\end{array}$ & 5.60 & 1.25 & $-0.87(0.09)$ & $0.80(0.17)$ & $0.65^{*}$ & 0.87 \\
\hline & $\begin{array}{l}\text { 6. After retiring I would: Loaf completely the } \\
\text { rest of my life/Do some of the exciting things } \\
\text { I have always wanted to do }\end{array}$ & 5.97 & 1.45 & $-1.67(0.09)$ & $2.57(0.17)$ & $0.48^{*}$ & 0.89 \\
\hline & $\begin{array}{l}\text { 7. My life is: Empty, filled with despair/Running } \\
\text { over with exciting good things }\end{array}$ & 5.39 & 1.24 & $-0.81(0.09)$ & $0.75(0.17)$ & $0.79^{*}$ & 0.86 \\
\hline & $\begin{array}{l}\text { 8. When thinking about my life I: Often wonder } \\
\text { why I exist/Always see a reason for my being here }\end{array}$ & 5.56 & 1.58 & $-1.09(0.09)$ & $0.65(0.17)$ & $0.77^{*}$ & 0.86 \\
\hline & $\begin{array}{l}\text { 9. I regard my ability to find a meaning, a } \\
\text { purpose, or mission in life as: Practically } \\
\text { none/Very great }\end{array}$ & 5.52 & 1.29 & $-0.86(0.09)$ & $0.63(0.17)$ & $0.75^{*}$ & 0.86 \\
\hline & $\begin{array}{l}\text { 10. I have discovered: No mission or purpose } \\
\text { in life/Clear-cut goals and a satisfying life purpose }\end{array}$ & 5.63 & 1.25 & $-0.91(0.09)$ & 0.87 (0.17) & $0.72^{*}$ & 0.87 \\
\hline
\end{tabular}

Note. In parenthesis, the standard error. PIL-10: Purpose in Life Test-10 Items.

${ }^{*} p<0.01$. 
TABLE 3 Fit indices for the PIL-A across gender and age

\begin{tabular}{|c|c|c|c|c|c|c|c|}
\hline & Model & $\mathrm{SB}^{2}(d f)$ & CFI & RMSEA [90\% Cl] & $\Delta \mathrm{SB \chi}^{2}(\Delta d f)$ & $\Delta \mathrm{CFI}$ & $\triangle$ RMSEA \\
\hline \multirow[t]{4}{*}{ Gender } & Baseline boys & $99.64(26)^{*}$ & 0.94 & $0.063[0.050,0.076]$ & & & \\
\hline & Baseline girls & $163.94(26)^{*}$ & 0.94 & $0.077[0.066,0.089]$ & & & \\
\hline & Configural & $265.05(52)^{*}$ & 0.94 & $0.072[0.063,0.080]$ & & & \\
\hline & Factor & $286.80(62)^{*}$ & 0.94 & $0.067[0.060,0.075]$ & $2.10(3)$ & 0.000 & 0.002 \\
\hline \multirow[t]{3}{*}{ Age } & Baseline $12-15$ years & $140.51(26)^{*}$ & 0.93 & $0.076[0.064,0.088]$ & & & \\
\hline & Baseline $16-19$ years & $114.30(26)^{*}$ & 0.95 & $0.064[0.052,0.076]$ & & & \\
\hline & Factor & $278.91(62)^{*}$ & 0.94 & $0.066[0.058,0.074]$ & $1.37(3)$ & 0.000 & 0.002 \\
\hline
\end{tabular}

Note. SBx ${ }^{2}$ : Satorra-Bentler Chi-square; $d f$ : degrees of freedom; CFI: Comparative Fit Index; RMSEA: Root Mean-Square Error of Approximation; PIL-A: Purpose in Life Test for Adolescents; $\mathrm{Cl}$ : confidence interval.

${ }^{*} p<0.01$.

TABLE 4 Standardized solutions for the PIL-A

Item

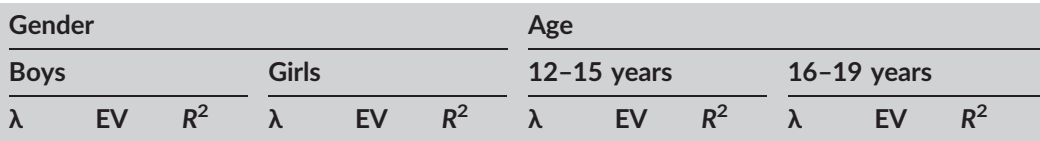

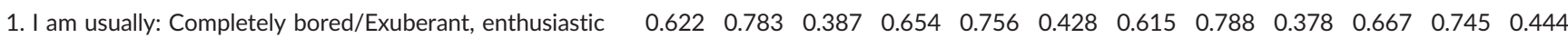

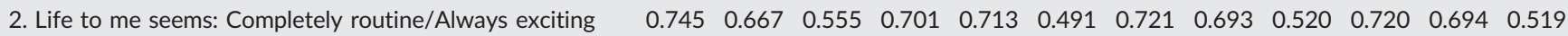

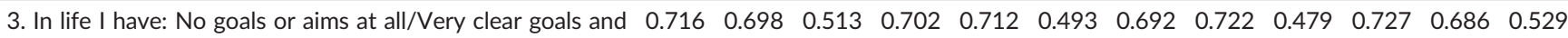
aims

4. Every day is: Exactly the same/Constantly new and $\begin{array}{lllllllllllllllll}0.661 & 0.750 & 0.437 & 0.649 & 0.761 & 0.421 & 0.634 & 0.773 & 0.402 & 0.681 & 0.732 & 0.464\end{array}$ different

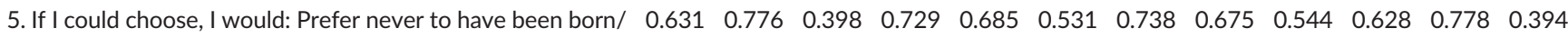
Like nine more lives just like this one

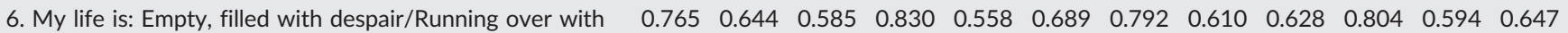
exciting good things

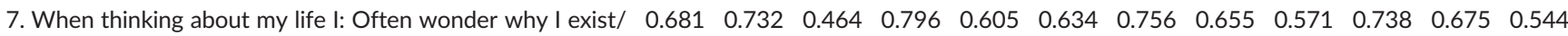
Always see a reason for my being here

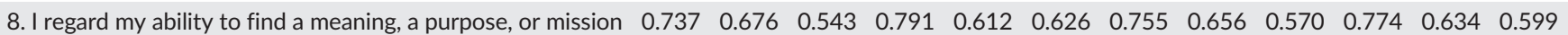
in life as: Practically none/Very great

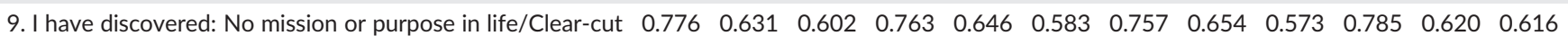
goals and a satisfying life purpose

$\begin{array}{llll}r_{(\mathrm{F} 1-\mathrm{F} 2)} & 0.78^{*} & 0.83^{*} & 0.81^{*}\end{array}$

Note. EV: error variance; PIL-A: Purpose in Life Test for Adolescents.

$* p<0.05$.

$M=46.64, S D=9.19 ; 16$ - to 19 -year-old group, $M=47.72, S D=8.68$;

boys, $M=46.85, S D=8.76$; girls, $M=47.49, S D=9.07$.

\subsection{Internal consistency of the PIL-A}

The PIL-A and the SML factor showed high internal consistency, $\alpha=0.89$ and $\alpha=0.85$, respectively, and the PGL factor showed good internal consistency, $\alpha=0.79$. The $C R$ confirmed good internal consistency of these scales: PIL-A, 0.87, SML, 0.79, and PGL, 0.72.

\subsection{Construct validity of the PIL-A}

\subsection{1 | Convergent validity}

The AVE values were good for both the SML and PGL factors, 0.71 and 0.75 , respectively, indicating good convergent validity of these scales.

\subsection{2 | Discriminant validity}

The squared correlation between the SML and PGL factors, $R^{2}=0.65$, was lower than the AVE values, indicating discriminant validity.

\subsection{Concurrent validity of the PIL-A}

To report the concurrent validity of the PIL-A, the correlations between this scale and the BHS and DERS were calculated. The PILA showed a strong negative correlation with both the BHS, $r=-0.64, p=0.000$, and the DERS, $r=-0.43, p=0.000$.

\section{7 | Differences in the PIL-A according to gender and age}

The difference in the PIL-A between boys and girls was not significant, $t=-1.42, p=0.157$, whereas the difference between the age groups 
was significant, with a small effect size, $t=-2.42, p=0.016, d=0.12$

(95\% Cl [0.023, 0.22]).

\subsection{Effect of MiL on the relationship between emotional dysregulation and hopelessness}

To test the hypothesis that MiL moderates the relationship between emotional dysregulation and hopelessness, hierarchical multiple regression was conducted. First, all the variables were standardized to make later interpretations easier and avoid multicollinearity. Then, a regression model was run, including emotional dysregulation and MiL as independent variables, and hopelessness as dependent variable. In the first step, emotional dysregulation and MiL accounted for a significant amount of variance in adolescents' hopelessness, $F(2$, 1231) $=498.62, p=0.000, R^{2}=0.45$. Next, the interaction term between emotional dysregulation and Mil was added to the regression model, which accounted for a significant percentage of the variance in adolescents' hopelessness, $F(3,1230)=375.65, p=0.000$, $\Delta R^{2}=0.031$. That is, there was a significant moderation of MiL between emotional dysregulation and hopelessness. The effect of emotional dysregulation on hopelessness was positive, $b=0.157$, $S E_{\mathrm{b}}=0.024, \beta=0.157, p=0.000$ : The higher the emotional dysregulation, the higher the hopelessness. However, the effect of MiL on hopelessness was negative, $b=-0.496, S E_{b}=0.023, \beta=-0.502$, $p=0.000$ : The higher the MiL, the lower the hopelessness. The moderation effect on hopelessness was negative, $b=-0.150, S E_{b}=0.018$, $\beta=-0.197, p=0.000$ : MiL showed a moderator effect between emotional dysregulation and hopelessness. Figure 1 plots the simple slopes for the interaction.

\section{4 | DISCUSSION}

The purpose of the present study was threefold: first, to analyse the psychometric properties of the PIL-10 (García-Alandete et al., 2013) in a Spanish sample of community adolescents; second, to analyse differences in age and gender groups; and third, to analyse the relationship between emotional dysregulation, MiL, and hopelessness. We hypothesized that the two original factors of the PIL-10 would be confirmed, that there would be no differences between boys and

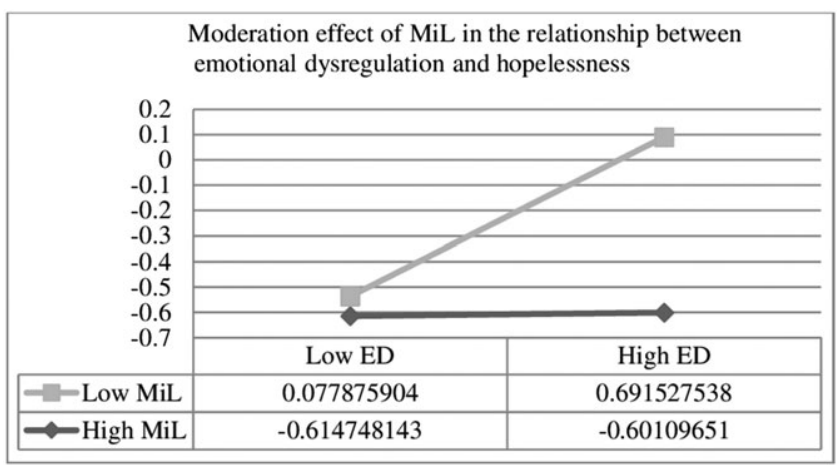

FIGURE 1 Moderation effect of meaning in life (MiL) in the relationship between emotional dysregulation and hopelessness girls in MiL, and that MiL would buffer the relationship between emotional dysregulation and hopelessness.

\section{1 | Structural validity of the PIL: A proposal of a version for adolescents with adequate psychometric properties}

Item 6 (After retiring, I would: Loaf completely the rest of my life/Do some of the exciting things I always wanted to do) was removed from the PIL-10 because the correlation with the scale was 0.50 , and the internal consistency increased without this item. Adolescents may have difficulty conceiving the term of retirement or empathizing with this developmental stage, or they may not have an adequate vision of what they are going to do when they retire or reach retirement. Studies say that the ability to extend the idea of time into the past and future develops with age (Green, Fry, \& Myerson, 1994), and both children and adolescents become more realistic about their expectations (e.g., Curtis, 2015; Sanders, 2013). For these reasons, Item 6 was eliminated to improve the factor structure of the instrument, reducing the number of items from 10 to 9 , and establishing a new version of the PIL, the so-called PIL-A. Therefore, this is the first study to perform confirmatory factor analysis of the PIL in adolescents. The two-factor model for the PIL-A showed an acceptable fit in the gender and age groups (male/female, 12-15 years/16-19 years), demonstrating configural invariance. Moreover, acceptable model fit was found for the metric invariance model, that is, equivalence of the factor loadings across groups. In sum, we obtained a nine-item version of the PIL in adolescents who show appropriate fit indices.

These results are similar to previous studies conducted with different populations showing that the two-factor solution is adequate for the PIL (e.g., García-Alandete et al., 2013; Jonsén et al., 2010; Melton \& Schulenberg, 2008). However, only a small number of studies have tested the structural invariance of MiL measures in multigroup comparisons. Van Ranst and Marcoen (1997) analysed the factorial validity and invariance of the Life Regard Index (Battista \& Almond, 1973) across samples of young and older adults, and they found that the former experienced lower MiL than the latter. Reker and Fry (2003) examined the factor structure and factorial invariance of six self-reported measures of MiL (including the Crumbaugh and Maholick, 1969, version of the PIL) in samples of younger and older adults, and they found that these six measures were structurally invariant across age for the first-order factor loadings, but the factors revealed no significant differences, although there was a tendency for older adults to experience higher MiL than young participants.

Furthermore, the PIL-A showed good construct validity (both convergent and discriminant validity), good internal consistency, and adequate concurrent validity, with strong negative correlations with the BHS and DERS: The higher the MiL, the lower the emotional dysregulation and hopelessness, agreeing with previous empirical evidence about the association between MiL and mental functioning (e.g., Halama \& Dedová, 2007).

Overall, these results show that the PIL-A is a scale with good psychometric properties for measuring MiL in adolescents. 


\subsection{Differences in MiL according to age and gender}

No significant differences in MiL were found between boys and girls, which is consistent with previous studies (e.g., Flood \& Boyd, 2008). Although very subtle, the difference between the means of the age groups was significant. This result is similar to previous studies and supports the idea that MiL increases over time (Reker, 2005; Steger et al., 2009).

It should be emphasized that this is the first study to analyse the psychometric characteristics of the PIL in a European population under 18 years of age, showing an adequate fit. This is quite important because MiL is associated with strong motivation and plays an important role in developing a goal-oriented life and predicting psychological and subjective well-being in adolescents (Côté, 2002; Damon, 2008; Rathi \& Rastogi, 2007). At the same time, it is a protective factor against negative patterns of behaviour, such as suicidal ideation, drug use, promiscuity, and eating disorders, among others (e.g., Brassai et al., 2011; Zhang et al., 2017). In addition, a lack of MiL is a risk factor for developing psychological distress and psychopathology (e.g., Butènaitè, Sondaitè, \& Mockus, 2016).

\section{3 | Effect of MiL on the relationship between emotional dysregulation and hopelessness}

The results obtained in the present study showed a significant and strong mediator role of $\mathrm{MiL}$ in the relationship between emotional dysregulation and hopelessness, reinforcing the positive role of MiL in mental health and as a resource for facing adversity. It is well known that emotional regulation plays a significant role in many psychological disorders, contributing to their development and maintenance (e.g., Kring \& Sloan, 2010). Moreover, emotional regulation can be considered a transdiagnostic psychopathological variable (e.g., Aldao, Gee, De Los Reyes, \& Seager, 2016; Fernandez, Jazaieri, \& Gross, 2016; Sloan et al., 2017), whereas MiL can be considered a transdiagnostic variable related to well-being, resilience, and protection from psychopathological symptoms. In this regard, MiL might be included in therapeutic settings with adolescents as a variable buffering emotional psychopathology related to mental disorders, in order to enhance the intervention outcomes. A sense of MiL can contribute to leading a satisfactory and functionally positive life and to giving adolescents with mental disorders the capacity to positively face adversity (e.g., Xin-qiang, Xiao-xin, Fan, \& Da-jun, 2016).

\section{5 | LIMITATIONS AND SUGGESTIONS FOR FURTHER RESEARCH}

Although this study presents a number of strengths, some limitations should be noted. First, because age and gender invariance of the PIL-A was tested in a cross-sectional analysis, the study design did not allow us to test the structural invariance across time. When invariance is demonstrated over time, any observed changes on individual PIL-A items can be attributed to real changes, and not to item instability. Future studies should track changes in PIL items in the same age groups at different points in time.
Second, the sample was composed of nonclinical participants. It would be useful to include clinical samples in future studies in order to compare them with nonclinical samples and further verify the psychometric properties of the PIL-A. This study opens the door to extending the research on MiL and psychopathological variables in the adolescent population. Likewise, it would be important to include sociocultural variables in order to better understand the role of MiL in adolescents (e.g., Davis \& Kiang, 2016).

Third, because this study was cross-sectional, as mentioned above, the relationship between emotional dysregulation and hopelessness, as well as the mediator role of MiL, was "static" rather than "dynamic." It would be important to carry out longitudinal studies in order to further examine the role of MiL in the relationship between emotional dysregulation and hopelessness (among other psychopathological variables;e.g., Henry et al., 2014; Van Tongeren, Hill, Krause, Ironson, \& Pargament, 2017) in diagnosed samples, as well as its therapeutic application and its role in the psychological treatment and daily functioning of adolescents. In the case of clinical samples of adolescents, according to Aldao (2016, p. 258), "the adoption of a developmental psychopathology approach [...] would allow one to identify risk and protective factors as well as sequential comorbidity."

\section{6 | CONCLUSION}

It is important to promote a sense of satisfaction with life and purpose, the clarification of personal identity and life goals, and empowerment in adolescents, in order to contribute to the feeling that their lives are meaningful, strengthen commitment to their lives, and protect them from psychopathology and risk behaviours (e.g., Brassai et al., 2015; Hill \& Burrow, 2012). Meaning-centred counselling applied to adolescents in the school setting could serve as a protective or preventive tool to increase MiL and reduce emotional dysregulation and its effect on hopelessness (e.g., Wong, 2012).

\section{ACKNOWLEDGEMENTS}

We would like to thank the anonymous reviewers for their valuable suggestions to improve the quality of this paper. We are also grateful to the subjects whose participation made this study possible.

\section{CONFLICT OF INTEREST}

No potential conflict of interest was reported by the authors.

\section{FUNDING INFORMATION}

This study did not receive any funding.

\section{ORCID}

Joaquín García-Alandete (D) http://orcid.org/0000-0003-0769-4060

José H. Marco-Salvador (D) http://orcid.org/0000-0002-1545-6452

\section{REFERENCES}

Aldao, A. A. (2016). Introduction to the special issue: Emotion regulation as a transdiagnostic process. Cognitive Therapy and Research, 40(3), 257-261. https://doi.org/10.1007/s10608-016-9764-2 
Aldao, A. A., Gee, D. G., De Los Reyes, A., \& Seager, I. (2016). Emotion regulation as a transdiagnostic factor in the development of internalizing and externalizing psychopathology: Current and future directions. Development and Psychopathology, 28(4), 927-946. https://doi.org/ 10.1017/S0954579416000638

Beck, A. T., Weissman, A., Lester, D., \& Trexler, L. (1974). The measurement of pessimism: The hopelessness scale. Journal of Consulting and Clinical Psychology, 42(6), 861-865. https://doi.org/10.1037/ h0037562

Bentler, P. M. (2006). EQS 6 structural equations program manual. Encino, CA: Multivariate Software, Inc.

Brassai, L., Piko, B. F., \& Steger, M. F. (2012). Existential attitudes and Eastern European adolescents' problem and health behaviors: Highlighting the role of the search for meaning in life. The Psychological Record, 62(4), 719-734. https://doi.org/10.1007/BF03395831

Brassai, L., Piko, B. F., \& Steger, M. F. (2015). A reason to stay healthy: The role of meaning in life in relation to physical activity and healthy eating among adolescents. Journal of Health Psychology, 20(5), 473-482. https://doi.org/10.1177/1359105315576604

Bronk, K. C. (2011). The role of purpose in life in healthy identity formation: A grounded model. New Directions for Youth Development, 132, 31-44. https://doi.org/10.1002/yd.426

Bronk, K. C., Hill, P. L., Lapsley, D. K., Talib, T. L., \& Finch, H. (2009). Purpose, hope, and life satisfaction in three age groups. The Journal of Positive Psychology, 4(6), 500-510. https://doi.org/10.1080/ 17439760903271439

Brouzos, A., Vassilopoulos, S. P., \& Boumpouli, C. (2016). Adolescent's subjective and psychological well-being: The role of meaning in life Hellenic Journal of Psychology, 13(3), 153-169.

Brown, T. A. (2015). Confirmatory factor analysis for applied research. New York, NY: Guilford Press.

Burrow, A. L., O'Dell, A. C., \& Hill, P. L. (2010). Profiles of a developmental asset: Youth purpose as a context for hope and well-being. Journal of Youth and Adolescence, 39(11), 1265-1273. https://doi.org/10.1007/ s10964-009-9481-1

Butènaitè, J., Sondaite, J., \& Mockus, A. (2016). Components of existential crisis: A theoretical analysis. International Journal of Psychology: Biopsychosocial Approach, 18, 9-27. https://doi.org/10.7220/2345024X.18.1

Caston, A. T., \& Mauss, I. B. (2011). Resilience in the face of stress: Emotion regulation as a protective factor. In S. M. Southwick, B. T. Litz, D. Charney, \& M. J. Friedman (Eds.), Resilience and mental health: Challenges across the lifespan (pp. 30-44). New York, NY: Cambridge University Press.

Chen, F. F. (2007). Sensitivity of goodness of fit indexes to lack of measurement invariance. Structural Equation Modeling, 14(3), 464-504. https://doi.org/10.1080/10705510701301834

Chen, K., Lay, K., Wu, Y., \& Yao, G. (2007). Adolescent self-identity and mental health: The function of identity importance, identity firmness, and identity discrepancy. Chinese Journal of Psychology, 49(1), 53-72.

Chesney, E., Goodwin, G. M., \& Fazel, S. (2014). Risks of all-cause and suicide mortality in mental disorders: A meta-review. World Psychiatry, 13(2), 153-160. https://doi.org/10.1002/wps.20128

Cheung, G. W., \& Rensvold, R. B. (2002). Evaluating goodness-of-fit indexes for testing measurement invariance. Structural Equation Modeling, 9(2), 235-255. https://doi.org/10.1207/S15328007SEM0902_5

Coffield, K. E., \& Buckalew, L. W. (1986). Student apathy: An analysis of relevant variables. College Student Journal, 20(2), 211-214.

Cohen, J. (1988). Statistical power analysis for the behavioral sciences (2nd ed.). New York, NY: Erlbaum.

Côté, J. E. (2002). The role of identity capital in the transition to adulthood: The individualization thesis examined. Journal of Youth Studies, 5(2), 117-134. https://doi.org/10.1080/13676260220134403

Crocetti, E., Rubini, M., Luyckx, K., \& Meeus, W. (2008). Identity formation in early and middle adolescents from various ethnic groups: From three dimensions to five statuses. Journal of Youth and Adolescence, 37(8), 983-996. https://doi.org/10.1007/s10964-007-9222-2

Crumbaugh, J. C. (1968). Cross-validation of Purpose in Life Test based on Frankl's concepts. Journal of Individual Psychology, 24(1), 74-81.

Crumbaugh, J. C., \& Maholick, L. T. (1969). Manual of instructions for the Purpose in Life Test. Saratoga, CA: Viktor Frankl Institute of Logotherapy.

Curtis, A. C. (2015). Defining adolescence. Journal of Adolescent and Family Health, 7(2), Article 2. Retrieved from http://scholar.utc.edu/jafh/vol7/ iss $2 / 2$

Damon, W. (2008). The path to purpose: How young people find their calling in life. New York, NY: Free Press.

Davis, R. F., \& Kiang, L. (2016). Religious identity, religious participation, and psychological well-being in Asian American adolescents. Journal of Youth and Adolescence, 45(3), 532-546. https://doi.org/10.1007/ s10964-015-0350-9

Fernandez, K. C., Jazaieri, H., \& Gross, J. J. (2016). Emotion regulation: A transdiagnostic perspective on a new RDoC domain. Cognitive Therapy and Research, 40(3), 426-440. https://doi.org/10.1007/s10608-0169772-2

Flood, M., \& Boyd, M. (2008). Successful aging in a southern older adult sample. Southern Online Journal of Nursing Research, 8(3). Retrieved from http://www.resourcenter.net/images/snrs/files/sojnr_articles2/ Vol08Num03Art06.pdf

Frankl, V. E. (1988). The will to meaning: Foundations and applications of logotherapy. New York, NY: Penguin.

Fu, Y., \& Law, Y. W. (2017). Chinese adolescents' meaning-focused coping with prolonged parent-child separation. Journal of Adolescent Research. Advance Online Publication. doi:https://doi.org/10.1177/ 0743558417700271

García-Alandete, J., Rosa, E., \& Sellés, P. (2013). Estructura factorial y consistencia interna de una version española del Purpose-In-Life Test [Factorial structure and internal consistency of a Spanish version of the Purpose-In-Life Test]. Universitas Psychologica, 12(2), 517-530. https://doi.org/10.11144/Javeriana.UPSY12-2.efc

Gratz, K. L., \& Roemer, L. (2004). Multidimensional assessment of emotion regulation and dysregulation: Development, factor structure, and initial validation of the difficulties in emotion regulation scale. Journal of Psychopathological Behavior, 26(1), 41-54. https://doi.org/10.1023/B: JOBA.0000007455.08539.94

Green, L., Fry, A. F., \& Myerson, J. (1994). Discounting of delayed rewards: A life-span comparison. Psychological Science, 5(1), 33-36. https://doi. org/10.1111/j.1467-9280.1994.tb00610.x

Gross, J. J. (2015). Emotion regulation: Current status and future prospects. Psychological Inquiry, 26(1), 1-26. https://doi.org/10.1080/ 1047840X.2014.940781

Hair, J. F., Anderson, R. E., Tatham, R. L., \& Black, W. C. (2006). Multivariate data analysis (6th ed.). Upper Saddle River, NJ: Pearson Prentice Hall.

Halama, P., \& Dedová, M. (2007). Meaning in life and hope as predictors of positive mental health: Do they explain residual variance not predicted by personality traits? Studia Psychologica, 49(3), 191-200.

Hansson, E., Daukantaité, D., \& Johnsson, P. (2017). Disordered eating and emotion dysregulation among adolescents and their parents. BMC Psychology, 5, 12. https://doi.org/10.1186/s40359-017-0180-5

Henry, K. L., Lovegrove, P. J., Steger, M. F., Chen, P. J., Cigularov, K. P., \& Tomazic, R. G. (2014). The potential role of meaning in life in the relationship between bullying victimization and suicidal ideation. Journal of Youth and Adolescence, 43(2), 221-232. https://doi.org/10.1007/ s10964-013-9960-2

Hervás, G., \& Jódar, R. (2008). Adaptación al castellano de la Escala de Dificultades en la Regulación Emocional [Spanish adaptation of the Difficulties in Emotional Regulation Scale]. Clínica y Salud, 19(2), 139-156.

Hill, P. L., \& Burrow, A. L. (2012). Viewing purpose through an Eriksonian lens. Identity: An International Journal of Theory and Research, 12(1), 74-91. https://doi.org/10.1080/15283488.2012.632394 
IBM (2013). IBM SPSS statistics for Windows, version 22.0. Armonk, NY: IBM Corp.

Ibraheim, M., Kalpakci, A., \& Sharp, C. (2017). The specificity of emotion dysregulation in adolescents with borderline personality disorder: Comparison with psychiatric and healthy controls. Borderline Personality Disorder and Emotion Dysregulation, 4, 1. https://doi.org/10.1186/ s40479-017-0052-x

Jackson, L. E., \& Coursey, R. D. (1988). The relationship of God control and internal locus of control to intrinsic religious motivation, coping and purpose in life. Journal for the Scientific Study of Religion, 27(3), 399-410. https://doi.org/10.2307/1387378

Jonsén, E., Fagerström, L., Lundman, B., Nygren, B., Vähäkangas, M., \& Strandberg, G. (2010). Psychometric properties of the Swedish version of the Purpose in Life Scale. Scandinavian Journal of Caring Sciences, 24(1), 41-48. https://doi.org/10.1111/j.1471-6712.2008.00682.x

Kring, A. M., \& Sloan, D. M. (2010). Emotion regulation and psychopathology: A transdiagnostic approach to etiology and treatment. New York, NY: Guilford.

Lent, R. W. (2013). Promoting meaning and purpose at work: A social-cognitive perspective. In B. J. Dik, Z. S. Byrne, \& M. F. Steger (Eds.), Purpose and meaning in the workplace (pp. 151-170). Washington, DC: American Psychological Association.

Lightsey, O. R. (2006). Resilience, meaning, and well-being. The Counselling Psychologist, 34(1), 96-197. https://doi.org/10.1177/ 0011000005282369

Mak, W. K., \& Shek, D. T. (1990). Sex differences in the psychological wellbeing of Chinese dual-employed parents in Hong Kong. CUHK Education Journal, 18(2), 115-120.

Matusiewicz, A., Weaverling, G., \& Lejuez, C. W. (2014). Emotion dysregulation among adolescents with borderline personality disorder. In C. Sharp \& J. L. Tackett (Eds.), Handbook of borderline personality disorder in children and adolescents (177-194). New York, NY: Academic.

McLaughlin, K. A., Hatzenbuehler, M. L., Mennin, D. S., \& NolenHoeksema, S. (2011). Emotion dysregulation and adolescent psychopathology: A prospective study. Behaviour Research and Therapy, 49(9), 544-554. https://doi.org/10.1016/j.brat.2011.06.003

Melton, A. M. A., \& Schulenberg, S. E. (2008). On the measurement of meaning: Logotherapy's empirical contributions to humanistic psychology. The Humanistic Psychologist, 36(1), 31-44. https://doi.org/ 10.1080/08873260701828870

Molasso, W. R. (2006). Exploring Frankl's Purpose in Life with college students. Journal of College and Character, 7(1), 1-9. Retrieved from www. tandfonline.com/doi/pdf/10.2202/1940-1639.1502

Ostrowski, T. M. (2015). Resiliency and the meaning of life. In T. Ostrowski, I. Sikorska, \& K. Gerc (Authors), Resilience and health in a fast-changing world (pp. 19-32). Jagiellonian University Press.

Perlman, G., Simmons, A. N., Wu, J., Hahn, K. S., Tapertm, S. F., Max, J. E., et al. (2012). Amygdala response and functional connectivity during emotion regulation: A study of 14 depressed adolescents. Journal of Affective Disorders, 139(1), 75-84. https://doi.org/10.1016/j. jad.2012.01.044

Ramgoon, S., Bachoo, S., Patel, C., \& Paruk, Z. (2006). Could a healthy ego identity serve as a protective factor against suicidal tendencies? A pilot study. Journal of Child and Adolescence Mental Health, 18(2), 49-54. https://doi.org/10.2989/17280580609486623

Rathi, N., \& Rastogi, R. (2007). Meaning in life and psychological well-being in pre-adolescents and adolescents. Journal of the Indian Academy of Applied Psychology, 33(1), 31-38.

Reker, G. T. (2005). Meaning in life of young, middle-aged, and older adults: Factorial validity, age, and gender invariance of the Personal Meaning Index (PMI). Personality and Individual Differences, 38(1), 71-85. https://doi.org/10.1016/j.paid.2004.03.010

Reker, G. T., \& Fry, P. S. (2003). Factor structure and invariance of personal meaning measures in cohorts of younger and older adults. Personality and Individual Differences, 35(5), 977-993. https://doi.org/10.1016/ S0191-8869(02)00312-4
Rosa, E., García-Alandete, J., Sellés, P., Bernabé, G., \& Soucase, B. (2012). Confirmatory factor analysis of the main models proposed for the Purpose-In-Life Test among Spanish undergraduates. Acta Colombiana de Psicología, 15(1), 67-76.

Sallee, D. T., \& Casciani, J. M. (1976). Relationship between sex drive and sexual frustration and purpose in life. Journal of Clinical Psychology, 32(2), 273-275.

Sanders, R. A. (2013). Adolescent psychosocial, social, and cognitive development. Pediatrics in Review, 34(8), 354-359. https://doi.org/10.1542/ pir.34-8-354

Sandhu, D., Singh, B., Tung, S., \& Kundra, N. (2012). Adolescent identity formation, psychological well-being, and parental attitudes. Pakistan Journal of Psychological Research, 27(1), 89-105.

Satorra, A., \& Bentler, P. M. (2001). A scaled difference chi-square test statistic for moment structure analysis. Psychometrika, 66(4), 507-514. https://doi.org/10.1007/BF02296192

Schulenberg, S. E., \& Melton, A. M. A. (2010). A confirmatory factor-anaIytic evaluation of the Purpose in Life Test: Preliminary psychometric support for a replicable two-factor model. Journal of Happiness Studies, 11(1), 95-111. https://doi.org/10.1007/s10902-008-9124-3

Shek, D. T. (1988). Reliability and factorial structure of the Chinese version of the Purpose in Life Questionnaire. Journal of Clinical Psychology, 44(3), 384-392. https://doi.org/10.1002/10974679(198805)44:3<384::AIDJCLP2270440312>3.0.CO; 2-1

Sloan, E., Hall, K., Moulding, R., Bryce, S., Mildred, H., \& Staiger, P. K. (2017). Emotion regulation as a transdiagnostic treatment construct across anxiety, depression, substance, eating and borderline personality disorders: A systematic review. Clinical Psychology Review, 57, 141-163. https://doi.org/10.1016/j.cpr.2017.09.002

Steger, M. F., Frazier, P., Oishi, S., \& Kaler, M. (2006). The Meaning in Life Questionnaire: Assessing the presence of and search for meaning in life. Journal of Counseling Psychology, 53(1), 80-93. https://doi.org/ 10.1037/0022-0167.53.1.80

Steger, M. F., Oishi, S., \& Kashdan, T. B. (2009). Meaning in life across the life span: Levels and correlates of meaning in life from emerging adulthood to older adulthood. The Journal of Positive Psychology, 4(1), 43-52. https://doi.org/10.1080/17439760802303127

Van Ranst, N., \& Marcoen, A. (1997). Meaning in life of young and elderly adults: An examination of the factorial validity and invariance of the Life Regard Index. Personality and Individual Differences, 22(6), 877-884. https://doi.org/10.1016/S0191-8869(97)00011-1

Van Tongeren, D. R., Hill, P. C., Krause, N., Ironson, G. H., \& Pargament, K. I. (2017). The mediating role of meaning in life in the association between stress and health. Annual of Behavioral Medicine, 51(5), 775-781. https://doi.org/10.1007/s12160-017-9899-8

Vandenberg, R. J., \& Lance, C. E. (2000). A review and synthesis of the measurement invariance literature: Suggestions, practices, and recommendations for organizational research. Organizational Research Methods, 3(1), 4-70. https://doi.org/10.1177/109442810031002

Vatan, S., Lester, D., \& Gunn, F. J. (2014). Emotion dysregulation, problemsolving, and hopelessness. Psychological Reports, 114(2), 647-651. https://doi.org/10.2466/20.02.PR0.114k23w3

Viñas, F., Villar, E., Caparrós, B., Juan, J., Cornellá, M., \& Pérez, I. (2004). Feelings of hopelessness in a Spanish university population: Descriptive analysis and its relationship to adapting university, depressive symptomatology and suicidal ideation. Social Psychiatry and Psychiatric Epidemiology, 39(4), 326-334.

Walters, L. H., \& Klein, A. E. (1980). A cross-validated investigation of the Crumbaugh Purpose-in-Life test. Educational and Psychological Measurement, 40(4), 1065-1071. https://doi.org/10.1177/ 001316448004000434

Wilchek-aviad, Y., \& Ne'eman-Haviv, V. (2018). The relation between a sense of meaning in life and suicidal potential among disadvantaged adolescent girl. International Journal of Offender Therapy and Comparative Criminology, 62(6), 1474-1487. https://doi.org/10.1177/ $0306624 \times 16684566$ 
Wilchek-Aviad, Y., \& Ne'eman-Haviv, V. (2016). Do meaning in life, ideological commitment, and level of religiosity, related adolescent substance abuse attitude? Child Indicators Research, 9(1), 261-276. https://doi.org/10.1007/s12187-015-9310-x

Wilchek-Aviad, Y., Ne'eman-Haviv, V., \& Malka, M. (2016). Connection between suicidal ideation, life meaning, and leisure time activities. Deviant Behavior, 38(6), 621-632. https://doi.org/10.1080/ 01639625.2016 .1197590

Wong, P. T. P. (2012). From logotherapy to meaning-centered counseling and therapy. In P. T. P. Wong (Ed.), The human quest for meaning: Theories, research, and applications (2nd ed.) (pp. 619-647). New York, NY: Routledge.

Wong, P. T. P. (2016). Meaning-seeking, self-transcendence, and wellbeing. In A. Batthyány (Ed.), Logotherapy and existential analysis: Proceedings of the Viktor Frankl Institute Vienna ( ed., Vol. 1) (pp. 311-321). Vienna, Austria: Springer.

World Health Organization (2003). Adolescent friendly health services: An agenda for change. Geneve, Belgium: Author.
Xin-qiang, W., Xiao-xin, H., Fan, Y., \& Da-jun, Z. (2016). Structure and levels of meaning in life and its relationship with mental health in Chinese students aged 10 to 25. Journal of Pacific RIM Psychology, 10(e10), 1-12. https://doi.org/10.1017/prp.2016.7

Zhang, R., Li, D., Chen, F., Ewalds-Kvist, B. M., \& Liu, S. (2017). Interparental conflict relative to suicidal ideation in Chinese adolescents: The roles of coping strategies and meaning in life. Frontiers in Psychology, 8, 1010. https://doi.org/10.3389/fpsyg.2017.01010

How to cite this article: García-Alandete J, Gallego Hernández de Tejada B, Pérez Rodríguez S, Marco-Salvador JH. Meaning in life among adolescents: Factorial invariance of the purpose in life test and buffering effect on the relationship between emotional dysregulation and hopelessness. Clin Psychol Psychother. 2019;26:24-34. https://doi.org/10.1002/ срp. 2327 